\title{
A MODERNIDADE EM CRISE, A AMERICA LATINA EM QUESTÃO
}

\author{
Verónica Parrícia Aravena Cor \\ Denise Carval
}

\begin{abstract}
RESUMIO:
Este trabalho parte das transformaçōes ocorridas na modernidade, alicerce do pensam to ocidental, para pensar a contemporaneidade. Inieialmente, se procura Iraşar algur consideraços sobre o pensamento de Deseartes, tido como primeiro filosoto "moxierr de Hobbes, por formular uma teoria de Estado, de Locke, por trabalhar o conceito de it cado e Rousscatu, por pensar a comunidade. Para Boaventura de Sousa Santos, Fsta nercada c comunidade fariam parte do pilar da regulaçăo, um dos cixos da modernida
\end{abstract}

Num scgundo momento lentamos pensar a questāo da modernidade na Ámérica Lati em trùs monentos: na época das indiependẹncias; no começo deste século, quando se o bora uma critica ao positivismo, $\mathrm{e}$ na atualidade. E interessante notar gue neste debate lino-americano sobre a modernidade a temítica que subjaz é a da identidade.

Na terecira parte tentamos, de uma forma geral, pensar os processos que estho se confi rande no mundo atual, euja denominaça genética, globalizaçăo, indica o sentimento inexorabilidade que a acompanha. Pitra finalizar, tentamos citar tum exemplo que, acre tamos, paste ser lictu como uma alternativa contra-hegemônica ì globalizaç̧o.

\begin{abstract}
:
This essity stirts wilh the transformations that modernity - considered as the foundat of occidental thought - has gone through. to furlher reflect upon contemporanity. In ally, it ities to delinente some idfeas about: I) Descartes, considered is the first "mode philosopher, 2) Hobbes, as the formulator of a theory of the State; 3) Locke, for its use the concept of the mitket, and; 4) Roussenu, for its thoughts on community. According Buaventara do Sousa Santos, State, markel and communily integrate the column of re. lation, which is one of the axis of modernity.

In a second instance, we try to think ubout the question of modernity in Latin America, at ih parlicular moments: the time of independenoe; the beginnings of this century — when a ca cal perspective of positivism was ehaborated - and, cur days. It is interesting to notice 1 ha constant theme behind Latin-American debate on modernity is the question of identily:
\end{abstract}

Verónica Patrícia Aravena Cortes é doutoranda no Departamento de Sociologia da U: Sāo Paulo

Denise Carvalho é mestranda no Programa de Pós-graduação em Integração da Amé ca Latina da USP 
In at third instanoe we try to think, in a general way, the on going processes of the contemporary seenc. The generic name for these processes, globalization. shows that they appear logether with a sentiment of being inexorable. Finally, we point out an cxample that, we believe, can be sech as an counter-hegenonic alternative to globalization.

\section{INTRODUÇĀO}

O final do século XX parece nos convidar à reflexão. No mundo atual vivenciamos situações extremadas: numa época de alto desenvolvimento tecnológico convivemos com guerras, fome, doenças, etc. Nas últimas décadas, a ciência e a técnica, aliadas, se desenvolveram muito. No entanto, este desenvolvimento nāo se traduziu, necessariamente, em melhoria da qualidade de vida da humanidade em diversos sentidos. Hoje assistimos a realizaçōes que outrora eram imaginadas como produtos de fícçăo (cadastramento de gens, clonagens, cirurgias a laser, robótica, inteligência artificial, etc.), mas a vida de grande parte das pessoas continua em condiçôes subhumanas e a ciência parece náo dar conta disso. Este século conheceu e sofreu como nenhum outro as potencialidades destruidoras de produtos desta aliança entre ciência e técnica: armas biológicas, bombas atômicas e periculosidade do lixo atômico. E mesmo assim agimos como se o conhecimento fosse desejável por ele mesmo, independentemente dos seus fins e aplicaçōes.

Pensar o momento atual é um desafio, pois a proximidade dificulta o entendimento e, por vezes, o impacto dos acontecimentos pode nos deixar paralisados por um profundo pessimismo. Mas este desafio se torna uma obrigação para todos aqueles que nāo acreditam que o futuro esteja inexoravelmente dado.

Para analisit a contemporancidade, neste trabalho, decidimos voltar às raizes do pensamento ocidental. Assim, nossa primeira preocupação será esboçar os fundamentos da modemidade, levando-se em consideração que o momento atual pareceria ser de crise da racionalidade ocidental. A falência paradigmática ocorreria pelo năo cumprimento das promessas da modernidade. A promessa da filosofia das luzes de que o uso da razâo (luz natural) levaria a uma autonomia do sujeito se realizou, como diria Walter Benjamin, na forma de tragédia.

A seguir veremos como se deu o debate sobre a modernidade na América Latina em três momentos distintos: a independência, os ideais positivistas no fím do século XIX e o momento atual.

O momento atual é denominado de período da globalizaçāo, pois ele estaria caracterizado pela integraçăo $\mathrm{cm}$ escala mundial de capitais, mer- 
cados, pessoas e idéias. O pensamento dominante afirma que este é o de tino do mundo: a uniformização dos valores, dos desejos e da história.

Será que estamos trilhando de forma inevitável este caminho? Sc que não há alternativas? Estas inquietudes serão tratadas na última pé te, quando tentaremos mostrar alguma experiências esboçadas para s lucionar problemas localizados que fazem parte deste labirinto conter porîneo.

\section{A MELANCOLIA DA MODERNIDADE}

Muito já se escreveu sobre a modernidade. Mas é interessante t tomarmos algumas idéias deste momento fundador do pensamento or dental. Boaventura de Sousa Santos postula que a modernidade está a cerçada em dois pilares: o pilar da emancipação e o pilar da regulaçã O pilar da emancipaçio estaria composto pela tríade da moral prátic da racionalidade cognitiva instrumental da ciência e da racionalidas estético-expressiva. Nesta tríade a racionalidade cognitiva instrument tem desempenhado um papel preponderante, tendo impregnado as o tras duas formas de racionalidade. A coluna da regulaçóo estaria cor posta por três principios: Estado, mercado e comunidade. E o seu equ líbrio teria pendido em favor do mercado ou do Estado, dependendo c época (1995b, p.2).

Dado o importante papel que o pensamento racional tem desemp nhado no paradigma da modernidade, c interessante analisá-lo mais ate: tamente.

Na história da filosofia ocidental é consenso que Descartes func a modernidade. Para Hegel, por ter ele formulado a consciencia de si $\mathrm{r}$ flexiva, para Alexandre Koyré $(1986,18)$, pela idealizaçīo da geometı zação do espaço e a dissolução dos Kosmos finito, ou seja, a substitu çăo do espaço concreto da física pré-galilaica pelo espaço abstrato da $\mathrm{g}$ ometria euclidiana (mérito que dividiria com Galileu) e para Walter Beı jamin, pela cisão entre corpo e alma, tornando-os irreconciliáveis e o qu acaba também por separar irreconciliavelmente o homem e a natureza

Segundo Hegel, Descartes impōe uma filosofia própria, nāo ligac à filosofia aristotélica, independente da tradição, da tutela, do saber tran milido, da memória (que nos liga à infância, um momento menor) e dc sentidos (fonte do erro). Para Descartes tudo que é externo à razão é at toritário, é um poder ilegítimo, tal como as escolas e os livros.

Kuyré apontia que Descartes e Galileu nāo combateram teorias e 
roneas ou insuficientes, mas alteraram uma atitude intelectual, bastante natural, na época, substituindo-a por outra que năo o era de modo algum. A física moderna (que à luz das novas descobertas tornou-se clássica), originada pelo pensamento destes atutores, não é uma continuação da física medieval, mas situa-se num plano diferente.

O século XVII marca o desaparecimento das velhas crenças, supertiçốes ou mityicas e a entrada da natureza na ordem científica. Com Descartes temos uma transformaçâo no conceito de natureza. Se, para os gregos e medievais, a natureza seguia um telos imanente, na modernidade, o mundo é reduzido ì mecanicidade, à sua extensāo geométrica, para melhor dominá-la, pois a natureza é o reino do acaso, do inteiramente inexplicado, daquilo que não pode ser formulado pela razão. O projeto de desencantamento do mundo triunfa no século XVII, com a metafísica cartesiana: devemos nos tornar mestres e senhores da natureza.

O método cartesiano será o encadeamento ordenado das razóes que se faz entre intuiçôes evidentes, ou seja, consistirá em reduzir toda medida a uma colocação em série que, partindo do simples, faz aparecer as diferenças como graus de complexidade: o princípio do conhecimento é dividir e ordenar. Isto trará grandes consequeencias para o pensamento ocidental. O semelhante que fora categoria fundamental do saber se acha dissociado numa análise feita em termos de identidade e diferença (Foucault, 1990 , p.65-73). A similitude não é mais experiência fundamental, mas antes, ocasião do erro.

A partir de entăo nāo haverá mais equilibrio. Haverá tensão e luta, pois vai se querer dominar o hermetismo da natureza.

Neste momento está sendo germinada a promessa de progresso. Segundo Descartes, a raz̄io pode aperfeiçoar o homem, pois the promete autonomia a libertá-lo do dominio das paixões. Na cisão antes impensada, corpo e espirito, o segundo terá maior importância, pois o corpo é um principio constante de distração e de vertigem.

Para Walter Benjamin, a melancolia é conatural à razño. $O$ olhar cartesiano quer ver tudo, principalmente os segredos da natureza, através da razăo. Para isso, oeu precisa ser pura transparência vazia, sujeito sem qualidades, interioridade despersonalizada. Assim, a melancolia acompanha o sujeito desprovido de sua personalidade (1984).

Maravall, no livro La cultura del barroco, postula que os homens, na primeira metade do século XVII, têm consciência de uma desordem intima e de uma crise social. As mudanças da modernidade são vistas como loucuras. O que é a loucura neste contexto? É o sentimento de que o mundo está ao revés porque ocorreu uma mudança na tradicional or- 
denaçāo do universo. Perdeu-se a crença na ordem de uma razão objeı va que mantém a justiça e a harmonia, o telos imanente.

Nesse contexto, o homem está em busca de alguma certeza, se sen como uma criatura "flutuante" que habita um universo grandioso, $\mathrm{m}$. sempre hostil e dominado pela fatalidade. Por isso existe a fixação no mecanismos, em projetar máquinas, nas construçāo artificiais e teóric: (Maravall, 1984).

No que se refere às relaçöes humanas, Hobbes trabalha o concei de Estado, o mercado é pensado por Locke, e, comunidade por Roussea Estes três contratualistas se baseiam em diferentes concepçóes de home: em estado de natureza para fundamentar os pactos e, por conseguint suas construcōes teóricas.

En Hobbes, o estado de natureza é definido como uma guerra iı cessante, tal como o sujeito barroco se percebe.O homem se encont: numa luta constante, pois a violência domina tanto a esfera privada corr. a esfera pública. As tragédias de Shakespeare são um exemplo desse $f_{1}$ nômeno na esfera privada, e as guerras da época na esfera pública. A. sim o Estado é uma construção artificial, mas necessária, pois os home ao introduzirem uma restrição para si mesmos estão pensando $\mathrm{cm}$ st conservaçăo, ou scja, no desejo de sair da condiçāo de guerra, que itr pera quando nâo há um poder visível capaz de mantê-los em respeitı forçando-os, por medo do castigo, ao cumprimento de seus pactos e a respeito às leis de natureza (fazer aos outros o que queremos que nos $\mathrm{f}^{\circ}$ çam) que por si só náo são obedecidas. O que torna o Estado capaz ć assegurar a paz c a defesa comum é a autoridade que cada indivíduo tt: confere, revestindo-o de poder e força. O terror que Leviatã inspira o torr capaz de conformar as vontades de todos os individuos (1983, p.107).

Rousseau reivindica a consciência da dignidade do homem, que nã se traduz no sentimento particularista do amor próprio, mas na unive: salidide do amor pelo gênero humano. Este amor é o elemento que lig o eu individual ao eu comum, ou seja, a vontade particular à vontade gera A realização concreta do cu comum e da vontade geral implicam neces sariamente um contrato social, ou seja, uma livre associaçāo de seres hu manos inteligentes, que deliberadamente resolvem formar um certo tip de sociedade, à qual passam a prestar obediência. O contrato social ser assim, a única base legítima para uma comunidade que deseja viver d acordo com os pressupostos da liberdade humana.

É necessario encontrar uma forma de associação que continue a res peitar essa liberdade que lhe dá origem. Embora o homem seja natura: mente bom, ele é constantemente ameaçado por forças que nāo só o alie 
nam de si mesmo como podem escravizá-lo. Assim sendo, Rousseau procura uma forma de associação na qual "cada um unindo-se a todos obedece, porém, apenas a si mesmo e permanece livre" lal como antes de estabelecer o contrato. As possibilidades de desigualdade e injustiça entre os cidadãos são evitadas mediante a "total alienaçào de cada associado, com todos os scus direitos, em benefício da comunidade" (1983, p.38).

Locke confere especial destaque à propriedade, um direito que considera natural. Este direito natural é anterior à sociedade civil, mas não inato. Sua origem reside na relação concreta entre o homem $\mathrm{c}$ as coisas, através do processo do trabalho. Se graças ao trabalho o homem transforma as coisas, para o autor, ele adquire o direito à propriedade: "Cada homem possui uma propriedade em sua propria pessoa. [...] $\mathrm{O}$ trabalho do seu corpo e a obri de suas mãos são propriamente dele" (1983, p.45). En lugar da oposiçẫo entre trabalho e propriedade, encontramos, em Locke, o trabalbo como origem fundamento da propriedade.

Assim o contrato entre homens livres tem como objetivo a preservaçno da vida, da liberdade e da propriedade, bem como de reprimir as violaçōes desses direitos naturais.

Estes dois pilares -emancipação e regulação- vão postular a harmonizaçăo de valores sociais potencialmente incompatíveis como justiça e autonomia, solidariedade e identidade, igualdade e liberdade. Desta forma, traz consigo um germe de frustraçăo.

No começo do século XIX, surge a idéia da emancipaçāo científjca e tecnológica da sociedade. A ciência se converte na instância moral suprema, acima do bem e do mal. O que caracterizaria o momento atual é a falência do pilar da emancipação.

A colonizaçion gradual das diferentes racionalidades da emancipacão moderna pela racionalidade cognitiva-instrumental da ciência levou a uma concentraçĩo das energias emancipatórias na aliança entre ciência e tecnologia. Até mesmo o marxismo se insere neste sistema de entendimento do mundo.

Hoje, temos a consciência de que a cientifizaçāo deixou de cumprir muitas promessas e de que até aprofundou algumas diferenças entre os homens.

\section{A MODERNIDADE NA AMÉRICA LATINA}

O debate sobre a modernidade nāo é indiferente à América Latina. Primeiro, porque a face atual da modernidade tem um estreito vínculo 
com o capitalismo, sendo que as perversas relaçôes econômicas e polí cas atingem de maneira particular os países periféricos. Segundo, pe fato da América Latina ter participado na produçāo da modernidade, $p c$ a decoberta do outro é um dos elementos que inaugura a era moderr Com a descoberta da América e dos americanos, os homens descob ram a totalidade de que fazem parte (Todorov, 1983, p.4).

\section{A independencia}

Segundo Anibal Quijano, a copresença da América Latina na pr dução da modernidade continua no seu período de cristalização, no s culo XVIII e início do século XIX. A promessa de emancipação, apes de estar presente nos dois lados do Atlântico, tem um sentido profunc neste continente, iá que a situaçăo colonial reforçou aqui o despotism a arbitrariedade, a desigualdade e o obscurantismo (Quijano, 1990, p.1\&

Na América, o movimento nacionalista de emancipaçāo é uma d: mais claras expressóes do movimento da llustração. A idéia de const tuiçấo de naçẫo, que emerge lentamente depois de um percurso de v: rios séculos na França revolucionária, vai se cristalizar na América L. tina sem que ela tenha passado pelo processo histórico que contribui para a lapidaçāo deste conceito. O primeiro ciclo de novas naçóes su ge nas Américas quando as colônias se emanciparam de suas metrópc les: primeiro os Estados Unidos, a seguir a maior parte da Améric Latina.

Opensamento hispano-americano principia como uma justificaçã da independência, mas se transforma quase que imediatamente num pre jeto: a Américá nāo é tanto uma tradição a ser seguida, mas, sim, um fi turo a ser realizado, como afirma o filósofo Jose Gaos. Proyecto y ute pia son inseparables en el pensamiento hispanoamericano desde fine del siglo XVII hasta nuestros dias (In: Paz, 1993, p.130).

A independência hispano-americana foi um acontecimento am bíguo e de difícil interpretaçĩo porque, tal como em outros episódios as idéias por vezes parecem mascarar a realidade em vez de esclarecê las. No movimento pela independência existiam duas tendências opos tas: uma de origem européia, liberal e utópica, que concebia a Améri ca espanhola como um todo unitário, assembléia de naçôes livres; outra, tradicional, que rompia os laços com a metrópole somente par acelerar o processo de dispersāo do Império (Bolivar, 1978, p.131). O grupos e classes que realizaram a independência na América do Sul per tenciam à aristocracia colonial nativa. Eram os descendentes dos co 
lonos espanhóis, colocados numa posiçāo de inferioridade frente aos próprios espanhóis. A metrópole aplicava uma política protecionista: por um lado impedia o livre comércio das colonias e obstruía seu desenvolvimento econômico e social mediante empecilhos administrativos. Por outro, afastava os crioulos que desejavam ocupar os altos empregos e a direção do Estado. Desta forma as lutas pela independência tendiam a liberar os crioulos da burocracia hispânica sem modificar a estrutura social das colônias. E o império espanhol se dividiu numa série de repúblicas por obra das oligarquias nativas que $\mathrm{cm}$ todos os lugares favoreccram o processo de desintegração.

Os ideais iluministas estavam presentes nos discursos dos intelectuais, mas, nesles territórios, as oligarquias crioulas não planejaram fundar uma nova naçĩo. Uma vez consumada a independência, as classes dirigentes se consolidam como herdeiras da velha ordem espanhola. Romperam com a Espanha mas se mostraram incapazes de criar uma sociedade moderna. Segundo o historiador Pedro Henrique Ureña, la novedad de las nuevas naciones hispanoamericanas es engañosa; en verdad se trata de sociedades en decadencia o en forzada inmovilidad stapervivências y fragmentos de todo un desecho (1990, p.57).

Quijano afirma que nesta época a América Latina e a Europa estavam preparadas para ingressar na modernidade. O que ocorreu foi que a América Latina foi vítima de uma relaçăo colonial com a Europa, ou, mais especificamente, com a Inglaterra. Para este autor, a Ilustração curopéia comportit desde seu início uma divisão: por uma lado estaria a promessa de liberação, difundida na Europa mediterrânea, e, por outro, um dispositivo instrumental de poder e de dominação, predominante na Europa nórdica. A hegemonia da lnglaterra significou a hegemonia da razão instrumental, obscurecendo-se a associação entre razão e liberaçắo. Para a América Latina esta inversāo foi catastrófica, pois elá năo pôde encontrar a modernidade senäo sob o signo de "modernizaçāo" (Quijano, 1990).

Os legisladores tentaram modificar as sociedades nascentes por decreto. Assim vemos que cada uma das novas naçôes teve, pouco tempo apús a independênciá, uma constituiçāo relativamente liberal e democrática. Contudo, se a formulaçano de uma legislação correspondia na Europa a uma realidade histórica - significava a expressão da ascensão da burguesia e a destruiçáo do ancien regime -, na América Latina, serviu para revestir com um verniz de modernidade a sobrevivência do sistema colonial. La mentira política se instaló en nuestros pueblos casi constitucionalmente (Ureña, 1990, p.57). 


\section{A Critica ao positivismo}

Nas últimas décadas do século XIX, a intelectualidade latino-an ricana se volta para uma doutrina que na França foi batizada por Augı to Comte com o nome de filosofia positiva. Os ideais positivistas don nam o cenário intelectual desses países até princípios deste século. conceito de evolução, que será aplicado tanto ao conhecimento da na reza física quanto ì ordem social e política servirá para justificar tants predomínio da burguesia como as reivindicaçoes do proletariado $\mathrm{cm}$ gente. En lo sustantivo, el positivismo fue sin embargo una doctrina losofica prohijada por las classes dirigentes de la América hispana el periodo de estableciniento y consolidación de capitalismo financ ro internacional en estos países (Salazar, p.20).

Já nas primeiras décadas deste século, alguns dos antigos repres tantes do pensamento positivista hispano-americano formulam uma : tocrílica a esta corrente e trabalham pela criaçáo de um movimento fi sófico autônomo no interior da Universidade latino-americana. Por e motivo estes intelcctuais foram denominados fundadores. Entre estes d tacam-se o argentino Alejandro Korn, o uruguaio Carlos Vaz Ferreirz chileno Enrique Molina, o peruano Alejandro Deustua e os mexica Jose Vasconcelos e Antonio Caso. E paralelamente atuam Jose Enric Rodó, Alfonso Reyes e Pedro Henriquez Ureña.

A questāo da raça é um tema primordial. Na era positivista a m tiçagem fora vista como o maior problema da América Latina. Para e geração, o signo se inverte.

O mexicano Alfonso Reyes vê como traço distintivo do americe um universalismo da inteligência. Jose Vasconcelos, seu contemporân acredita na existência de uma dimensāo universal do hispano-ameri no, produto de sua juventude e da sua mestiçagem, que poderia tradu: se numa filosofia com amplitude mundial. "Los iberoamericanos. hallamos como en el cruzamiento de todos los caminos. Los recién gados de la historia, pero tambien herederos de todas sus experien y de toda su sabiduria, somos como grano reconcentrado en el cual das las especies de plantas hubiesen puesio su esencia. De semeja concentración de gérmenes saldra todo un nuevo reino de vida" ( concelos, In: Salazar, p.89).

O filósofo mexicano Leopoldo Zea, a partir de seu artigo "En . no a la filosofia anericana", publicado em 1942, tem contribuído F o estudo da história das idéias na América. Na sua opinião, a essêr do indivíduo latino-americano nāo está dada pela cultura pré-coloml 
na e, por outro lado, "frente a la cultura europea nos sucede algo raro, nos servimos de ella, pero no la consideramos nuestra, nos sentimos imitadores de ella. Nuestro modo de pensar, nuestra concepción de mundo son semejantes a los del europeu. La cultura europea tiene para nosotros el sentido que carece la cultura precolombina. Y sin embargo no la sentimos nuestra. Nos sentimos como bastardos que usufructúan bienes a los que no tienen derecho (...) A Adoptanos sus ideas pero no podemos adaptarnos a ellas ... Nuestra concepción de mundo es europea, pero las realizaciones de esta cultura las sentimos ajena, al intentar realizar lo mismo en América, nos sentimos imitadores" (1978, p.283).

De acordo com Zea, o problema está em sentirmos o americano, o próprio, como algo inferior. O mal está em pretender adaptar a circunstância americana a uma concepção de mundo herdada da Europa e năo adaptar esta concepçīo de mundo à realidade americana. Mas também esta situaçấo inevitável pode ser útil "si América no ha hecho wna cultura propia es porque no lo ha necesitado; si ha vivido como eco y sombra de una cultura ajena, ha sido porque en esta forma resolvió mejor los problemas de su circuntancia" (idem, p.286). Acreditamos ser bastante temerário afirmar que a América Latina poderia ter resolvido seus problemas adaptando soluçōes emprestadas. O próprio autor, ao sentir a crise européia dos anos 40 , provocada pela II Guerra, percebe a necessidade de buscar o que é propriamente americano na vida histórica. Tratase de buscar e ressaltar aquilo que é nosso, superando o sentimento de inferioridade e a tendência à imitaçāo e de potencializar nossa capacidade de universalismo como resposta à intolerância dos nacionalismos.

\section{O MUNDO NUMA EPPOCA DE GLOBALIZAÇÃO}

É corrente a referência ao momento atual como um período de globalização, pois ele estaria caracterizado pela integraçio em escala mundial de capitais, mercados, pessoas e idéias. Contudo, parece um equívoco pensar que este fenômeno seria um ponto distintivo da contemporaneidade. Todo modelo capitalista desenvolvido a partir do mercantilismo é um movimento de globalização. A partir do século XIX isto se tornou muito nítido. Neste sentido, parece mais correto dizer que o moderno sistema mundial, dentro do qual se insere a globalização das interaçōes sociais, vem desde o século XVI, e todas as recentes transformaçóes nos campos legal, cultural, social, político e econômico devem ser localizadas neste processo histórico. 
Mas, sem dúvida, este fenômeno é de natureza diversa do que ocor reu no século passado com a formação dos Estados Nacionais, quand. foram criadas as fronteiras e, nos terrritórios nacionais, foram travada batallas de homogenizaçâo e uniformidade em nome de uma cultura na cional. Na verdade, esta cultura nacional vista mais de perto era a ex pressâo de uma cultura hegemônica. Ela combina uniformidade com di ferenciaçấo local, padróes culturais impostos de cima e outros criado no campo popular. Não pode ser entendido através de uma explicaçã monocausal ou unidimensional.

Para Boaventura de Sousa Santos, a globalizaçāo é um processo al tamente complexo c ambíguo que espelha a complexidade e a ambigüi dade do processo de transnacionalização. O processo não é linear, ne. vas formas de globalizaçăo ocorrem junto com novas ou renovadas for mas de localizaçăo. De fato, como interdependências globais e inter ção intensificada, as relaçōes sociais, em geral, parecem tornar-se des territorializadas, abertas a novos direitos de opçāo, cruzando todo o eix até os dominados pelos costumes, nacionalismo, linguagem e ideologia frequientemente por todas elas juntas. E, por outro lado, e em aparent contradị̧ăo, novas identidades regionais, nacionais e locais estāo eme gindo e são construidas em torno da nova proeminência dos direitos existir (1995b).

Se o momento atual faz parte de um processo que já dura alguns se culos, o que nos leva entäo a sentir que vivemos numa época diferente?

Nas últimas três décadas, as interações transnacionais têm se re produzido com dramática intensificaçâo, desde a mundialização dos sis temas de produçấo e transferências financeiras até a disseminação mur dial da informaçüo e imagens através dos meios de comunicaçăo de mass (mídia) c tecnologias comunicacionais, e, por outro lado, a translocaçã em massa de pessoas, como turistas, trabalhadores imigrantes ou refug ados. A extraordinária vastidâo e profundidade dessas interaçôes tranı nacionais levou alguns autores a ver nela um ponto de partida para nc vas formas de relaçōes mundiais, que receberam o nome de "globaliz: ção". "formação global" ou "cultura global". Giddens define globaliz: ção como "a intensificação das relaçōes sociais mundiais as quais liga localidades distantes de tal forma que acontecimentos locais divides espaço com eventos ocorrendo há milhares de quilometros distante e vica versa" (Giddens, 1901).

É preciso notar que a globalização das duas últimas décadas năo sa guiu o padrāo de uniformizaçāo e homogenizaçấo previsto pelo paradign da modernidade, mas antes combinou a aplicaçăo de modelos mundiais cor 
a diversidade locil, identidide nacional e étnica das comunidades.

No campo das relaçōes econômicas existe uma nova divisāo do trabalho baseada na globalização da produção conduzida pelas coorporaçóes transnacionais que são os agentes-chaves na nova economia mundial. As novas características deste novo mundo econômico săo: fontes mundiais ampliadas, sistemas flexíveis de produçăo e baixos custos de transportes facilitando a produção de componentes industriais na periferia c a sua exportaçāo para o centro; emergência de três grandes blocos comerciais: um com base nos Estados Unidos, outro tendo o Japão como eixo c a Comunidade Européia. (Sousa Santos, 1995b)

No campo cultural a questão central gira em torno da emergência ou nāo de uma cultura mundial ou global nas últimas décadas. Ou seja, deseja-se saber se têm emergido, nos últimos tempos, formas culturais que sejam originalmente transnacionais ou cujas origens nacionais são relativamente irrelevantes, já que elas circulam por todo o globo desenraizadas de suas culturas nacionais.

Cabe notar que a idéia de uma cultura global é certamente o principal projeto da modernidade. No entanto, a atençấo dada nestas duas últimas decadas a esta idéia em vários campos - comunicação, geografia, sociologia, filosofia, entre outras - tem como base a dramática intensificação dos fluxos por todo o sistema - bens, capitais, trabalho, pessoas, idéias e informação - que se traduz em convergencias, hibridizaçōes entre as diferentes culturas nacionais, sejam elas estilos arquitetônicos, moda, hábitos alimentícios ou consumo cultural massificado.

Segundo Renato Ortiz, a cultura mundializada transcende as naçōes, as classes sociais e os grupos, permeando toda a rede de forças sociais, culturais, comunicacionais, revelando-se através da vida cotidiana, onde o consumo é o cixo articulador do processo e sua principal instância de legitimaçăo de comportamentos e valores.

Refletir sobre a globalização, segundo Renato Ortiz, é, de alguma maneira, refletir sobre as transformaçốes do espaço e o tempo. A aceleraçāo deste movimento transforma nossas idéias. Trata-se de uma radical e profunda mudança. Hoje fica muito mais dificil pensar em identidades culturais com fronteiras claramente delimitadas; os povos e as naçóes não poden mais se definir exclusivamente em contraposiçāo aos outros. A idéia de um nós se transformou (Ortiz, 1995, p.10).

Este dado da globalizaçāo também é tratado por Milton Santos, que acredita que os sistemas técnicos criados recentemente se tornaram mundiais, mesmo que sua distribuiçāo geográfica scja, como antes, irregular e o seu uso social seja hierárquico. Mas, pela primeira vez na história do 
homem, nos defrontamos com um único sistema técnico, o meio té co-científico-informacional é a nova face do espaço e do tempo. É aí se instalam as atividades hegemônicas, aquelas que têm relaçôes n longínquas e participam do comércio internacional, fazendo com que terminados lugares se tornem mundiais ao mesmo tempo em que tor outros lugares mais localizados.

Milton Santos postula que essa unidade no espaço em escala : bal tem como réplica a unificação do tempo. Nos encontramos num ríodo histórico no qual os momentos convergem, pois, dada a insta: neabilidade das transmissốes, a qualquer minuto pode-se saber o que. acontecendo simultaneamente num outro canto do planeta $(1994, \mathrm{p}$. No período atual, a produção de um fato e seu consumo coinciderr tempo e no espaço. Hoje os acontecimentos do dia-a-dia sāo interder dentes, relacionados e simultâneos.

Para o pesquisador, o espaço se globaliza, mas não é mundial cc um todo, senâo como metáfora. Todos os lugares sâo mundiais, mas há espaço mundial. Quem se globaliza mesmo são as pessoas e os luga

As cidades globais, que assinalam elos e momentos básicos da balizaçăo, localizam-se em países hegemônicos ou secundários. Né discussão, Santos adiciona que a um tempo hegemônico corresponc atores e açōes hegemônicas e a um tempo năo hegemônico corresp dem atores e ações năo hegemônicas. Grupos, instituiçōes e indivíd convivem juntos, mas não praticam os mesmos tempos.

Segundo Octavio Ianni, a sociedade global envolve outra reali de histórica, geográfica, demográfica, antropológica, política, econô ca, social, cultural, religiosa e linguística. Cabe refletir sobre as moc caçỏes que essa nova realidade incute na sociedade nacional, levan se em conta as alteraçôes ocorridas em seus dois eixos centrais: o es co e o tempo.

Estamos vivendo num mundo em que questōes que outrora dizi respeito ao âmbito nacional já ampliaram suas fronteiras. Para Ianni, " poucos a morfologia da sociedade global envolve direitos humanos, $r$ cotráfico, proteção do meio ambiente, dívida externa, saúde, educaç meios de comunicação de massa, satélites e outros itens. Assuntos sc ais, econômicos, políticos e culturais que sempre pareceram nacion internos, logo se revelam internacionais, externos, relativos à harmo da sociedade global" (Ianni, 1992, p.43).

E preciso notar que o Estado-naçăo é um processo histórico, 1 ma-se c conforma-se, afirma-se e transforma-se, integra-se e rompe. Seria ilusório, segundo lanni, imaginar que dada sociedade nacional ar 
dureceu, realizou-se, tornou-se irreversivel, adquiriu uma forma definitiva (Idem, p.70).

Nesse sentido, o Estado-naçāo torna-se paulatinamente anacrônico devido à dinâmica e à força das relaçôes, processos e estruturas que se desenvolvem em escala mundial. As naçóes transformam-se em espaços, territórios ou elos da sociedade global. Esta é a nova totalidade em movimento, problemática c contraditoria. Assim como cria inibiçôes e produz anacronismos, também deflagra novas condiçóes, para uns e outros, indivíduos, grupos, classes, movimentos, naçốes, nacionalidades, culturas, civilizaçoes. Cria outras possibilidades de ser, agir, pensar e imaginar (Idem, p.5]).

Milton Santos formula o questionamento sobre a natureza de nação. As naçôes que existem se confundem com um pedaço de território. E o que sabemos das naçóes que atualmente se conformam? Serão o rearranjo e a reconstituição de antigas lealdades ou de atributos herdados? Será a cidade uma naçāo? (1993, p.37-38)

Por outro lado, segundo Renato Ortiz, dizer que as referências nacionais se tornam mais diluídas, nāo significa que elas irão desaparecer. O processo de globalização da sociedade pode até mesmo supervalorizar o tema da nação. É o caso do retorno de valores nacionais em vários países. Por ser o processo de globalizaçāo irreversível, ele se choca com os interesses nacionais, Daí uma retomada do nacional. Trata-se menos da "construção nacional", como era entendida, e mais de uma reação a algo que se apresenta como inexorável. Em outros contextos acontece o inverso: um fortalecimento do local em detrimento do nacional. $\mathrm{O}$ importante é entender que o processo de globalizaçăo da sociedade redefine as relaçōes culturais entre os povos, etnias e culturas. A mundialização da cultura não cria apenas o "internacional-popular". Ela traz também novas hierarquias, novas formas de discriminação social. A modernidade-mundo legitima a desigualdade planetária na consciência e na imaginação dos homens (1995, p.12).

O antropólogo Néstor Garcia Canclini considera que o desafio atual é reconceifualizar a identidade cultural levando $\mathrm{cm}$ conta a reorganização dos mercados e consumos. Ele postula que as idéias, tradicionalmente utilizadas para entender o processo de formaçăo de uma identidade nacional, devem ser colocadas em questão num mundo em que prima a desterritorializaçăo que é dada por uma formação híbrida cultural do homem atual.

O autor formula a seguinte questăo: ¿Qué significan las identidades nacionales en un tiempo de transnacionalización e interculturalidad, 
de coproduciones multinacionales y exposiciones "Paris-Berlín acuerdos de ibre comercio o integraciones económicas regionales, de las obras, los artistas y los capitales atraviesan constantemen. fronteras? (1991, p.1) Ao analisar a produção cultural latino-amt na, o autor se defronta com um mundo em processo de transnaciona ção, desterritorialização e hibridação, e pede que as definições est e as práticas artísticas sejam repensadas pelos intelectuais, bem co tradicional paradigma que opóe o centro desenvolvido a uma per marginalizada.

A cultura mundializada está muito distante de levar a uma c ra global. Sob as condiçōes dadas pelo sistema mundial, o global é uma globalização bem-sucedida de um dado localismo. Seg Boaventura de Sousa Santos, dada a natureza hierárquica do sis mundial, torna-se crucial identificar os grupos, classes, interes Estados que definem culturas particulares como culturas globais, ta forma passando a agenda para dominação política sob o non globalizaçấo cultura].

O autor identifica quatro tipos de globalização, dois no âmbi leitura subparadigmática (adaptativa ao capitalismo) e dois no âmbi leitura paradigmática (com proposta de transformação social).

No âmbito da leitura subparadigmática encontramos o global localizado, que consiste na globalização de um fenômeno local exemplo, a fast food norte-americana) e o localismo globalizado consiste no impacto específico das práticas e imperativos transnaci, nas condiçōes locais que săo desestruturadas e reestruturadas para ponder aus imperativos transnacionais (exportaçăo de madicira par gamento da divida externa chilena). Os países centrais especializa se em globalismos localizados, enquanto que, aos paises periférico ram impostos us localismos globalizados.

Já no âmbito da leitura paradigmática das tranformaçổes glı em processo, encontramos o cosmopolitismo e a herança comum d manidade.

O cosmopolitismo consiste numa rede de esforços locais pro sivos com o objetivo de maximizar o potencial emancipatório atrav conexōes translocais e locais (por exemplo, a utilização da Internet Movimento Zapatista de Libertação Nacional). Segundo Sousa S: năo há um globalismo genuíno, a não ser aquele que se relaciona c sustentabilidade da vida humana na terra. $O$ autor "toma emprest do Direito Internacional a noção de herança comum da humanidade definir este tipo de globalismo (1995 b). 


\section{ALTERNATIVAS PARA AÇÖES CONTRA-HEGEMIONICAS}

A transnacionalização dos problemas enfrentados pelas sociedades contemporâneas exige, paradoxalmente, soluçóes cada vez mais localizadas. Isso se deve ao fato do enfraquecimento do Estado-naçâo na sua capacidade de intervir na definição e manutenção das políticas nacionais, principalmente quando relativas ao bem-estar dos cidadãos. Soma-se também o fato da existência de grande diversidade cultural, que demanda soluçôes que possam responder às especificidades locais.

As transformaçóes na correlação de forças entre o projeto que visava à manutenção do sistema capitalista e aquele que visava à superaçāo desta ordem, desarticularam os setores que buscavam a subversăo da ordem constituida. Com o colapso do projeto comunista, o inimigo antes totalmente identificado, toma uma forma difusa, o que agrava ainda mais a crise de capacidade emancipatória dos setores populares. Houve um esvaziamento das lutas dos trabalhadores, pois para muitos é preferível estar inserido num sistema de desigualdade do que inexistir em outro de exclusăo.

As forças emancipatórias continuam se mobilizando, embora a capacidade de organizaçāo de alguns setores, como o operariado, seja bastante inferior à facilidade e agilidade com que o capital se organiza transnacionalmente. No entanto, resistir é sempre preciso, pois o futuro năo está necessariamente definido. Trava-se uma luta desigual, já que o paradigma emergente se confronta com um paradigma dominante, embora

em crise. E urgente reiventar a possibilidade de futuro em bases distintas daquelas da modernidade.

Boaventura de Sousa Santos nos propōe a utopia como base de reinvenção do futuro. "A exploração de novas possibilidades e vontades humanas, por via da oposição, da imaginação à necessidade do que existe, só porque existe, em nome de algo radicalmente melhor que a humanidade tem direito de desejar e porque merece a pena lutar" (1995a, p.278).

A constituição da modernidade resultou em diversos epistemicídios. Oautor postula que há tantas formas de conhecimento quanto as práticas sociais que as geram e as sustentam. Devemos voltar a aprender com o Sul, ou seja, com os oprimidos e historicamente silenciados.

Selecionamos um exemplo de ação concreta dentro do espaço-tempo da cidadania que constitui uma experiência contra-hegemônica de cosmopolitismo. O Orçamento Participativo é uma ação de administraçóes públicas municipais, procurando, de maneira localizada, democratizar a relaçāo Estado/cidadão. 


\section{Orçamento Participativo}

A participação popular na elaboração do orçamento municipal recente no Brasil. Historicamente a decisấo sobre os elementos que tituem o orçamento é tomada pelos prefeitos e secretários. $\mathrm{O}$ cid que paga os tributos e e o principal interessado nos serviços pres pelo poder público, fica de fora do processo decisório.

Os resultados da elaboração do orçamento "de cima para baix conhecidos: investimentos marcados pelos imediatismos, critérios c oridade duvidosos e de repercussão financeira ambígua, prática $c$ entelismo político, exercido tanto pelo Poder Executivo quantc Poder Legislativo, etc.

O orçamento-programa das prefeituras brasileiras sempre foi instrumento para cumprimento das exigências legais de contabilid

Apesar da prática do Orçamento Participativo ter sido introd no Brasil na gestāo de 1985 a 1988 pela Administração Democrá Popular de Diadema, no Estado de São Paulo, o discurso do "pla mento participativo", "democracia participativa" e "governo parti tivo" é antigo. Muitas vezes os esforços de democratizar as decisō bre os investimentos realizados nas cidades foram sinceros, mas c sultados foram sempre ambíguos. Mesmo quando a populaçāo era da năo obtinha retorno de suas reivindicaçôes. Muitas vezes, aper parcelas que interessavam aos governos eram convidadas a parti Em outros casos as "propostas de participação" ocorriam apenas no: mentos eleitorais para proporcionar um canal de contato direto c população. Desta forma, caíram em descrédito junto às lideranças c nitárias empenhadas na transformação social.

Nas três últimas gestōes administrativas municipais $(85 / 88$, \{ e 93/96), as administraçōes municipais do campo democrático e F lar vêm radicalizando o processo do Orçamento Participativo. Ele é tece em capitais como Belo Horizonte, Porto Alegre, Rio Branco e ânia e em cidades pequenas e médias como Betim, Ipatinga, São Jos Campos, Santos, Diadema, Ribeirão Preto, Londrina, etc. Foi, tam implantado em 1995 no Estado do Espírito Santo e no Distrito Fed

O Orçamento Participativo é uma experiência política inédita siderada por muitos, como a mais importante iniciativa de descen zaçăo, de democratização do poder e de envolvimento popular nas . sōes que, historicamente, eram consideradas atribuiçôes dos gove Trata-se de uma forma pública de poder, nāo estatal, mas civil. Att do Orçamento Participativo o cidadāo, individual ou coletivamente, 
trola e induz o poder municipal ou estadual e seus investimentos. Desta forma, o setor público passa a ser um instrumento a serviço da maioria da populaçāo. Ao mesmo tempo cm que o governo transforma-se em algo mais transparente e acessivel, a comunidade adquire novos valores de cidadania elevando seu nivel de consciência política c social.

Com o Orçamento Participativo um novo paradigma foi introduzido na relação de parceria e gestāo conjunta entre sociedade e governos municipal e estadual. Diversas pesquisas de opinião realizadas nas cidades acima re acionadas demonstram que o Orçamento Participativo é uma das iniciativas mais apreciadas pelas populaçoes das cidades governadas pelas administraçōes de partidos do campo progressista.

\section{CONCLUSÃO}

Ao reconstituir, parcialmente, os caminhos trilhados pela modernidade, encontramos o pensamento cartesiano como o marco que lança as bases da modernidade que se configura na atualidade. Descartes acredita que todo poder à margem da razăo é autoritário e ilegítimo. Paradoxalmente, o resultado da primazia cartesiana é um outro autoritarismo. Encontramos na metafísica cartesiana o ínicio de transformação da relação do homem com a natureza.

O cartesianismo nega a outras formas die conhecimento, como a semelhança, o papel de experiência fundamental ocupado até então. Com a adoção do método que busca o conhecimento através do encadeamento ordenado das razōes que se dá entre intuiçōes evidentes, reduzindo toda medida a uma colocaçăo em série do mais simples ao mais complexo, destitui o semelhante em detrimento da identidade e da diferença. O pensamento cartesiano encerra uma promessa de progresso, que será concretizada através do domínio da natureza. Tudo deve, agora, ser visto através da razâo.

Hobbes considera o Estado, uma construção artificial, necessário para que a ordem seja estabelecida entre os homens. Só o Estado é capaz de inspirar o temor para que os pactos entre os homens sejam cumpridos.

Rousseau trabalha o conceito de comunidade. Para que a realização do eu comam e da vontade geral ocorra é necessário um contrato social que seja uma livre associação de seres humanos inteligentes que, deliberadamente, resolvem formar um determinado tipo de sociedade à qual prestam obediência. 
Locke considera a propriedade um direito natural, anterior à s. dade civil, porém não inato. É o trabalho que fundamenta o direito à priedade.

O paradigma da modernidade nāo cumpriu suas promessas eı cipatórias. A crescente cientificidade, decorrente da aliança entre , cia e tecnologia e da colonizaçăo gradual das diversas racionalidad. moderna emancipaçāo pela racionalidade congnitiva-instrumental c ência, levou a humanidade a uma enorme frustração, além de ter : fundado as diferenças entre os homens.

Quando nomeamos o processo atual, que ocorre em escala mu al como globalização, estamos nos referindo à integração em escala netária de capitais, mercados, pessoas e idéias. Esse processo não é 17 pois está em curso desde o desenvolvimento do modelo capitalist: senvolvido a partir do mercantilismo.

Complexo c ambíguo, o processo de globalização está longe de jar uma cultura global. A globalização cultural é, sem dúvida, uma ma de dominaçío política. Neste contexto, os setores historicamente ginalizados do planeta devem buscar formas contra-hegemônicas d ganizaçāo global.

O vínculo atual da modernidade com o capitalismo faz com c América Latina esteja fortemente inserida neste debate. Mesmo po a América Latina foi partícipe da produção da modernidade, pois a coberta do outro é um dos seus clementos constitutivos.

A América Latina conheceu a modernidade sob o signo da " dernização", já que a hegemonia da razão instrumental se consoli obscurecendo a associação entre razão e liberação. Nosso continente conseguiu escapar dos efeitos nefastos dessa hegemonia, uma vez mantinha uma relação colonial com a Europa.

Canclini propóe, como utopia atual latino-americana, uma rá nalidade alternativa, que não seja um desencantamento do mundo, $\mathrm{c}$ a inteligibilidade de sua totalidade.

Nós aqui apresentamos uma experiência brasileira como um ternativa que busca contribuir para o processo de transformação so Na verdade, está inscrita no âmbito do capitalismo, sem questioná-l، truturalmente, mas pode somar-se ao esforço de esboçar um novo $\mathrm{F}$ digma, pois năo se submete à ordem imposta pelo poder hegemônic

O Orçamento Participativo é uma experiência política inédit País. É considerada por muitos como a mais importante iniciativa de centralização, de democratização do poder e de envolvimento pof nas decisões que, historicamente, eram consideradas atribuiçóes dc 
verno. Trata-se de um importante avanço democrítico na relaçăo entre população e Estado.

\section{BIBLIOGRAFIA}

BENJAMIN, Walter. A origem do Drama Barroco Alemāo. Coleçāo Elogio da Filosofia. São Paulo: Brasiliense, 1984.

BOLIVAR, Simon. Discurso de Angostura in VVAA - O pensamento latinoamericano. México: Siglo XXI ed.s, 1978.

BRUNNER, Jose Joaquin. América Latina en la encrazijada de la modernidad. Santiago, Chile: FLACSO, Série Educación y Cultura, $n^{22} 22,1992$.

CANCLINI, Nestor Garcia. Redefiniciones - Arte c identidad en la época de las culturas postnacionales. Conferência apresentada no Simpósio "Identidade cultural ná América Latina", no Memorial da América Latina, Sāo Paulo, set. de 1991 .

CARPENTIER, Alejo. O Reino deste mundo. Rio de Janeiro: Civilizaçû́o Brasileira, 1985.

CHIAMPI, Irlemar. In: Lezama Lima, A expressão americana, Săo Paulo: Brasiliense, 1988.

DESCARTES, Renc. Discurso do Mérodo. São Paulo: Coleção Os Pensadores, ed. Nova Cultura, 1988.

FOUCAULT, Michel. As palavras e as coisas. Sāo Paulo: Martins Fontes, 1990.

GIDDENS, Anthony. As conseqüiencias da modernidade. Marília: UNESP, 2aed., 1991.

IANNI, Octavio A sociedade global. Rio de Janeiro: Civilização Brasileira, 1992.

HOBBES, Thomas. Leviaiá. São Paulo: Coleçî̀ "Os Pensadores", Abril Cultural, 1983.

LOCKE, John. Segundo Tratado do Governo. Sũo Paulo: Coleçấo "Os Pensadores". Abril Cultural. 1983

MARAVALL, Jose Antonio. La cultura del barroco. Barcelona: Ed. Ariel, 1983.

KOIRÉ, Alexandre. Estridos galilaicos. Lisboa: OPUS, Biblioteca de Filosofia, 1986.

PAZ, Octavin. El laberinto de la soledad. México: Fondo de Cultura Económica, 2a ed. Col. Popular. 1993.

QUIJANO, Anibal. "Modernidad, Identidad y Utopia en América Latina." in Imágenes Desconocidas. Buenos Aires, Argentina: CLACSO, 1990.

ROUSSEAU, Contrato Social, in Coleção Os Pensadores. Ed. Nova Cultural.

SALAZAR, Augusto Bondy, Existe una filosofia de mestra América? México: Siglo XXI Editores, 1968. 
SANTOS, Boaventura de Sousa. Towards a new common sense. Now Routledge, la ed. 1995.

Pela mão de Alice. São Paulo: Cortez Editora, 1995.

SANTOS, Milton. Técnica, espaço, tempo. São Paulo: Hucitec. 1994.

SANTOS, M., SOUZA, M. A., SCARLATO, F.C. c ARROYO, M. $O$ mapa do mundo. Fin de século e globalização. São Paujo; Hucitec-A 1993.

() novo mapa do mundo. Globalizaçäo e espaço latino-ameri São Paulo: Hucitec-Anpur. 2a ed., 1994.

TODOROV, Tzvetan. A conquista da América. Sāo Paulo: Ed. Martins Fॄ́ $3 a$ cd., 1993.

URENA A. Pedro Henriquez. Historia de América Latina. México: Fondo de rura Economica. $5^{2}$ ed. 1990.

ZEA, Leopoldo. Anérica Laina: 500 anos. México: Fondo de Cultura Es mica, 1000.

- Notas sobre la inteligencia Americana in VVAA - Opensamente no-americano. México: Siglo XXI ed.s, 1978. 